\title{
Super Harmonic Mean Labeling Of Joins Of Square Of Path Graph
}

\author{
S.Sriram ${ }^{1}$, Dr.R.Govindarajan ${ }^{2}$ \\ ${ }^{I}$ Assistant Professor, Department of Mathematics, Patrician College of Arts and Science, Adyar, Chennai ${ }^{1}$,Head \\ ${ }^{2}$ Associate Professor(Retd), P.G and U.G Department of Mathematics, D.G Vaishnav College, Arumbakkam, \\ Chennai ${ }^{2}$ \\ Email:sanksriram@gmail.com ${ }^{l}$
}

\begin{abstract}
Let $\mathrm{G}=(\mathrm{V}, \mathrm{E})$ be a graph with $\mathrm{p}$ vertices and $\mathrm{q}$ edges. A graph $\mathrm{G}=\{\mathrm{V}, \mathrm{E}\}$ with $\mathrm{p}$ vertices and $\mathrm{q}$ edges is said to be a super Harmonic mean graph if it is possible to label the vertices $x \in V$ with distinct labels by an injective function $\mathrm{f}(\mathrm{x})$ from $1,2, \ldots \mathrm{p}+\mathrm{q}$ in such a way that when each edge $\mathrm{e}=\mathrm{uv}$ is labelled with $f(e=u v)=\left\lceil\frac{2 f(u) f(v)}{f(u)+f(v)}\right\rceil$ or $\left\lfloor\frac{2 f(u) f(v)}{f(u)+f(v)}\right\rfloor$

and if $\mathrm{f}$ is such that $f(V(G)) \cup\{f(e) / e \in E(G)=1,2, \ldots p+q\}$. In this case $\mathrm{f}$ is called Super Harmonic mean labelling of G. In this paper we have identified Square of Path graph $P_{n}^{2}$ and attached an edge to form a join to the square of path graph $P_{n}^{2}$ and proved that the join of square of path graph $P_{n}^{2}$ is Super harmonic mean labelling and also have exhibited some important results connecting the joins of square of path graph $P_{n}^{2}$.
\end{abstract}

Keywords- Square of Path graph $P_{n}^{2}$,Super Harmonic Mean labelling, Super Harmonic Mean graph, Joins of Square of path graph $P_{n}^{2}$

\section{INTRODUCTION}

A graph $\mathrm{G}$ is a finite nonempty set of objects called vertices and edges. All graphs considered here are finite, simple and undirected. Gallian J. A [1] has given a dynamic survey of graph labelling. The origin of graph labellings can be attributed to Rosa. The vertex set is denoted by $\mathrm{V}(\mathrm{G})$ and the edge set is denoted by $\mathrm{E}(\mathrm{G})$. Mean Labelling of graphs is introduced by .Somasundaran S and Ponraj R [2] and Sandhya S S, .Somasundaram S and Ponraj.R [3,4,5 ]introduced Super Harmonic mean labelling of graphs and also worked on harmonic mean labelling of cycle related graphs. Motivated towards the labelling of Super Harmonic mean labelling of graphs we have identified the Square of path graph $P_{n}^{2}$ tried to attach edge to the square of path $P_{n}^{2}$ graph to form a chain of square of path graph $P_{n}^{2}$ which we call as Join of square of path $P_{n}^{2}$ graph.. In this paper we intend to prove that the Join of square of path $P_{n}^{2}$ graph is Super Harmonic Mean labelling graph and we exhibit some important results connecting the joins of a square of path $P_{n}^{2}$ graph. The concepts that we refer to graph labelling is from handbook of graph theory [6].

\section{PRELIMINARIES}

Definition 2.1: $A$ graph $G=\{V, E\}$ with $p$ vertices and $\mathrm{q}$ edges is said to be a super Harmonic mean graph if it is possible to label the vertices $x \in V$ with distinct labels by an injective function $\mathrm{f}(\mathrm{x})$ from 1,2 , $\ldots \mathrm{p}+\mathrm{q}$ in such a way that when each edge $\mathrm{e}=\mathrm{uv}$ is labelled with $f(e=u v)=\left\lceil\frac{2 f(u) f(v)}{f(u)+f(v)}\right\rceil$ or $\left\lfloor\frac{2 f(u) f(v)}{f(u)+f(v)}\right\rfloor$ and $\quad$ if $\mathrm{f}$ is such that
$f(V(G)) \cup\{f(e) / e \in E(G)=1,2, \ldots p+q\}$. Definition .2.2: For a path graph $P_{n}$ with vertices $u_{1}, u_{2}, \ldots u_{n}$ the square of path $P_{n}^{2}$ graph with $\mathrm{n}$ vertices $u_{1}, u_{2}, \ldots u_{n}$ and $2 \mathrm{n}-3$ edges

Definition .2.3 : For a path graph $P_{n}$ with vertices $u_{1}, u_{2}, \ldots u_{n}$ the square of path $P_{n}^{2}$ graph with $\mathrm{n}$ vertices $u_{1}, u_{2}, \ldots u_{n}$ and $2 \mathrm{n}-3$ edges we attach an edge to each of square of path $P_{n}^{2}$ graph with another square of path $P_{n}^{2}$ graph and define it as 1join square of path $P_{n}^{2}$ graph. 


\section{Available online at www.ijrat.org}

Note: The number of vertices of 1 -join square of path $P_{n}^{2}$ graph has $2 n$ vertices and $4 n-5$ edges

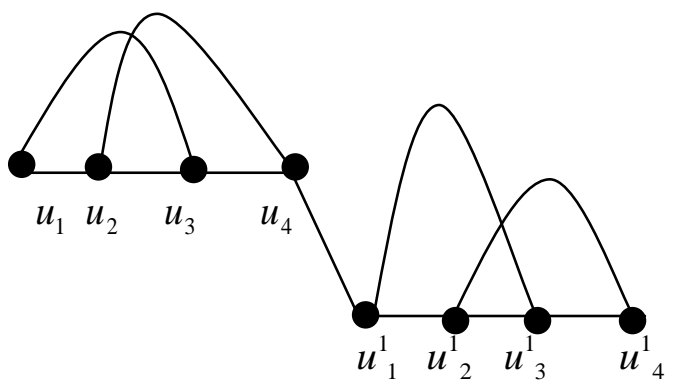

Figure.1: 1-Join square of path $P_{4}^{2}$

The above 1 -join of square of path $P_{4}^{2}$ graph with 4 vertices and 5 edges attached by an edge to one square path graph $P_{4}^{2}$ with another square path graph $P_{4}^{2}$. Similarly we can construct 2 -join square of path by attaching one more edge with another square path graph $P_{4}^{2}$. Continuing this way we get a chain of M-join of square of path $P_{4}^{2}$ graph. Similarly we can construct for any square of path $P_{n}^{2}$ graph and can call it as M-join of square of path $P_{n}^{2}$ graph.

Note : We here exclusively study the case of M-Join of square of path $P_{n}^{2}$ graph attached by edges $e_{1}, e_{2}, \ldots, e_{n}$ respectively one each to one square of path $P_{n}^{2}$ graph to square of path $P_{n}^{2}$ graph where $\mathrm{n}$ is of same length. So that the number of edges connected in each of square of path $P_{n}^{2}$ is maintained to be the same.

\section{MAIN RESULTS}

Theorem .3.1: The 1- Join square of path $P_{n}^{2}$ graph is a Super Harmonic Mean graph.

Proof: Let G=1-Join of square of path $P_{n}^{2}$ graph

Let us prove that $\mathrm{G}$ is a Super Harmonic Mean graph Let us prove the theorem by labelling the vertices of the graph $\mathrm{G}$.

We have the number of vertices in square of path $P_{n}^{2}$ graph is $n$ and the number of edges is $2 n-3$. Now adding one edge between the square of path $P_{n}^{2}$ graph with another square of path $P_{n}^{2}$ graph we have the number of vertices in 1-Join of square of path $P_{n}^{2}$ graph is $2 \mathrm{n}$ and the number of edges in 1-Join of square of path graph is $4 n-5$.
Now let us label the vertices of 1 -join of square of path $P_{n}^{2}$ graph as follows. We know that the first square of path $P_{n}^{2}$ has n vertices and second square of path $P_{n}^{2}$ has n vertices and totally 2 n vertices is to be labelled.

Let us denote the Vertex Set of first square of path $P_{n}^{2}$ graph as $V=\left\{u_{1}, u_{2}, u_{3}, u_{4}, \ldots u_{n}\right\}$ and the vertex set of second square of path $P_{n}^{2}$ graph as $V^{1}=\left\{u_{1}^{1}, u_{2}^{1}, u_{3}^{1}, u_{4}^{1} \ldots u_{n}^{1}\right\}$. The edge set of first square of path $P_{n}^{2}$ graph is $E=\left\{e_{1}, e_{2}, e_{3}, e_{4}, \ldots e_{n-1}\right\} \cup\left\{e_{i j}, 1 \leq i \leq n-2, j=i+2\right\}$ and the edge of the second square of path $P_{n}^{2}$ Graph is

$E^{1}=\left\{e_{1}{ }^{1}, e_{2}{ }^{1}, e_{3}{ }^{1}, e_{4}{ }^{1}, \ldots e^{1}{ }_{n-1}\right\} \cup\left\{e^{1}{ }_{i j}, 1 \leq i \leq n-2, j=i+2\right\}$

Now by adding one edge between the first and second square of path $P_{n}^{2}$ graph we have the vertex set of 1Join square of path $P_{n}^{2}$ graph as $V(G)=\left\{u_{1}, u_{2}, u_{3}, u_{4}, \ldots u_{n}\right\} \cup\left\{u_{1}^{1}, u_{2}^{1}, u_{3}^{1}, u_{4}^{1} \ldots u_{n}^{1}\right\}$ and the edge set as $E(G)=\left\{e_{1}, e_{2}, e_{3}, e_{4}, \ldots e_{n-1}\right\} \cup\left\{e_{1}{ }^{1}, e_{2}{ }^{1}, e_{3}{ }^{1}, e_{4}{ }^{1}, \ldots e^{1}{ }_{n-1}\right\}$ $\cup\left\{e_{i j}, e^{1}{ }_{i j}, 1 \leq i \leq n-2, j=i+2\right\} \cup\{e\}$

The edges that are connecting between the first and second square of path $P_{n}^{2}$ graph are known as

$e_{i}=u_{i} u_{i+1}$ for $1 \leq i \leq n-1$

$e_{i}^{1}=u_{i}^{1} u_{i+1}^{1}$ for $1 \leq i \leq n-1$

$e_{i j}=u_{i} u_{j}$ for $1 \leq i \leq n-2$ and for $\mathrm{j}=\mathrm{i}+2$

$e_{i j}{ }^{1}=u_{i}{ }^{1} u_{j}{ }^{1}$ for $1 \leq i \leq n-2$ and for $\mathrm{j}=\mathrm{i}+2$

$e=u_{n} u_{1}^{1}$

Now let us label the vertices of first square of path $P_{n}^{2}$ graph in correspondence to the vertices of second square of path $P_{n}^{2}$ graph as follows

$f\left(u_{i}\right)=2 i-1$ for $1 \leq i \leq n$

$f\left(u^{1}{ }_{j}\right)=2(n+j)+1$ for $1 \leq j \leq n$

Now we can compute the induced edge labelling as follows

$f^{*}\left(e_{i}\right)=f^{*}\left(u_{i} u_{i+1}\right)=\left\lceil\frac{2 f\left(u_{i}\right) f\left(u_{i+1}\right)}{f\left(u_{i}\right)+f\left(u_{i+1}\right)}\right\rceil$ or $\left\lfloor\frac{2 f\left(u_{i}\right) f\left(u_{i+1}\right)}{f\left(u_{i}\right)+f\left(u_{i+1}\right)}\right\rfloor$ 


\section{E-ISSN: 2321-9637}

\section{Available online at www.ijrat.org}

$$
\begin{aligned}
& f^{*}\left(e_{i}^{1}\right)=f^{*}\left(u_{i}^{1} u_{i+1}^{1}\right)=\left\lceil\frac{2 f\left(u_{i}^{1}\right) f\left(u_{i+1}^{1}\right)}{f\left(u_{i}^{1}\right)+f\left(u^{1}{ }_{i+1}\right)}\right\rceil \\
& \text { or }\left\lfloor\frac{2 f\left(u_{i}^{1}\right) f\left(u_{i+1}^{1}\right)}{f\left(u_{i}^{1}\right)+f\left(u_{i+1}^{1}\right)}\right\rfloor \\
& f^{*}\left(e_{i j}\right)=f^{*}\left(u_{i} u_{j}\right)=\left\lceil\frac{2 f\left(u_{i}\right) f\left(u_{j}\right)}{f\left(u_{i}\right)+f\left(u_{j}\right)}\right\rceil \\
& \text { or }\left\lfloor\frac{2 f\left(u_{i}\right) f\left(u_{j}\right)}{f\left(u_{i}\right)+f\left(u_{j}\right)}\right\rfloor \\
& f^{*}\left(e_{i j}{ }^{1}\right)=f^{*}\left(u_{i}{ }^{1} u_{j}{ }^{1}\right)=\left\lceil\frac{2 f\left(u_{i}{ }^{1}\right) f\left(u_{j}{ }^{1}\right)}{f\left(u_{i}^{1}\right)+f\left(u_{j}^{1}\right)}\right\rceil \text { or } \\
& \left\lfloor\frac{2 f\left(u_{i}^{1}\right) f\left(u_{j}{ }^{1}\right)}{f\left(u_{i}^{1}\right)+f\left(u_{j}^{1}\right)}\right\rfloor \\
& f^{*}(e)=f^{*}\left(u_{n-1} u_{1}^{1}\right)=\left\lceil\frac{2 f\left(u_{n-1}\right) f\left(u_{1}^{1}\right)}{f\left(u_{n-1}\right)+f\left(u_{1}^{1}\right)}\right\rceil \\
& \text { or }\left\lfloor\frac{2 f\left(u_{n-1}\right) f\left(u_{1}^{1}\right)}{f\left(u_{n-1}\right)+f\left(u_{1}^{1}\right)}\right\rfloor
\end{aligned}
$$

Hence the induced edge labelling can be found to be distinct and hence it can be claimed that the given graph $\mathrm{G}$ is Super Harmonic mean labelling graph. Hence the proof.

Example.3.2: The 1-Join square of path $P_{4}^{2}$ is super harmonic mean graph

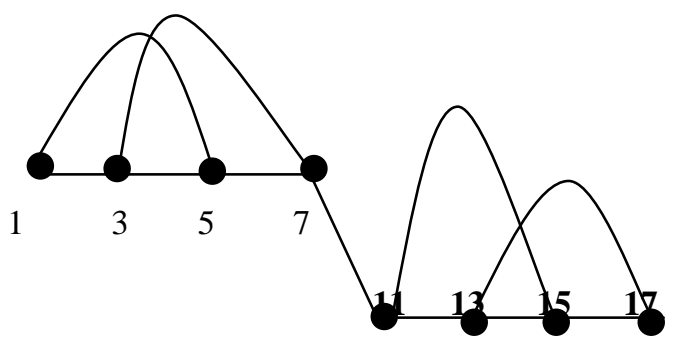

Theorem.3.3: If graph G is a M-Join square of path $P_{n}^{2}$ graph then

Number of Vertices in M-Join square of path $P_{n}^{2}$ graph $=(M+1)(n)$ and

Number of edges in M-Join square of path $P_{n}^{2}$ graph $=2 \mathrm{n}(\mathrm{M}+1)-(2 \mathrm{M}+3)$ for all $\mathrm{n}$ where $\mathrm{M}$ is the number of Joins in square of path $P_{n}^{2}$ graph of length n.

Proof: Let us prove the theorem by Method of Mathematical induction
Let us prove for the first positive integer i.e $M=1$, the number of joins in a square of path $P_{n}^{2}$ graph.

Given the graph $\mathrm{G}$ is 1 - Join square of path $P_{n}^{2}$ graph then according to the construction of the 1--Join of square of path $P_{n}^{2}$ graph we have the number of vertices $=2 n$ and the number of edges $=4 n-5$ Now for $M=1$

Number of vertices in 1-Join square of path $P_{n}^{2}$ graph $=(M+1)(n)=2 n$ and hence it is true

Number of edges in 1-Join square of path $P_{n}^{2}$ graph $=4 \mathrm{n}-5=2 \mathrm{n}(\mathrm{M}+1)-(2 \mathrm{M}+3)$

Hence the induction holds good for $M=1$

Now let us assume that it is true for $M=k$, where $k$ is the number of joins

Number of vertices in k-join square of path $P_{n}^{2}$ graph $=(\mathrm{k}+1)(\mathrm{n})$ and

Number of edges in k-join square of path $P_{n}^{2}$ graph $=$ $2 \mathrm{n}(\mathrm{k}+1)-(2 \mathrm{k}+3)$

Now let us prove for $\mathrm{M}=\mathrm{k}+1$

i.e. $M=k+1$ means that the number of joins is $k+1$

We know that the number of joins $\mathrm{k}+1=$ number of $\mathrm{k}$ joins + number of 1 join of square of path $P_{n}^{2}$ graph.

We have assumed that it is true for $\mathrm{k}$ joins

Hence number of vertices in $\mathrm{k}+1$-join square of path $P_{n}^{2} \operatorname{graph}=(\mathrm{k}+1)(\mathrm{n})+2 \mathrm{n}=(\mathrm{k}+3) \mathrm{n}$

Number of edges in $\mathrm{k}+1$-join of square of path $P_{n}^{2}$ graph $=2 \mathrm{n}(\mathrm{k}+1)-(2 \mathrm{k}+3)+2 \mathrm{n}-2$

Which on simplifying

Number of edges in k+1-join of square of path $P_{n}^{2}$ graph $=2 \mathrm{n}(\mathrm{k}+1)+2(\mathrm{n}-\mathrm{k})-5$

Hence the proof of induction. Therefore the theorem is true for M-Joins of square of $P_{n}^{2}$ graph.

Definition.3.4: Sum of the vertices of square of path $P_{n}^{2}$ graph is $n^{2}$ as the vertices are labelled with odd numbers and hence they form an arithmetic progression with common difference 2 .

Theorem.3.5 : For any M-Join of square of path $P_{n}{ }^{2}$ graph the Sum of the vertices of M- Join is given as a finite series $n^{2}+\sum_{i=1}^{M} n\left(n+d_{i}\right)$ for M-joins, where $\mathrm{n}$ denotes the number of vertices and $d_{1}=u_{1}{ }^{1}-u_{1}$, $d_{i}=u_{1}^{i}-u_{1}^{i-1}$ for $2 \leq i \leq M$.

Proof: Let $\mathrm{G}$ be a graph of square of path $P_{n}^{2}$ graph . We know the sum of the vertices of square of path $P_{n}^{2}$ is $n^{2}$ as the vertices are labelled with odd numbers. Now for each join of square of path $P_{n}^{2}$ 


\section{Available online at www.ijrat.org}

graph we have to compute the sum of the vertices it can be understood that from the labelling procedure adopted for proving the 1 -join of square of path $P_{n}^{2}$ graph that the difference between $d_{1}=u_{1}{ }^{1}-u_{1}$ can be computed and hence the sum of 1- join square of path $P_{n}^{2}$ graph can be found to be $n^{2}+n\left(n+d_{1}\right)$. Similarly for each join of square of path $P_{n}^{2}$ we compute the difference between

$d_{i}=u_{1}^{i}-u_{1}^{i-1}$ for $2 \leq i \leq M$ and hence can be added to the sum of 1 -join of square of path $P_{n}^{2}$ graph resulting in the sum of $\mathrm{M}$-join of square of path $P_{n}^{2}$ graph to be $n^{2}+\sum_{i=1}^{M} n\left(n+d_{i}\right)$. Hence the proof.

Corollary.3.6: For any M-Join of square of path $P_{n}^{2}$ graph sum of the each of the join added increases by $n\left(n+d_{i}\right)$ where $1 \leq i \leq M$ from the sum of the square of path $P_{n}^{2}$ graph whose sum is $n^{2}$

Proof: From Theorem.3.4 it can be seen that the sum of the vertices of M-Join of square of path $P_{n}^{2}$ graph is $n^{2}+\sum_{i=1}^{M} n\left(n+d_{i}\right)$. From the proof of the theorem it is trivial to understand that each of the join increases the sum by $n\left(n+d_{i}\right)$ for $1 \leq i \leq M$. Hence the proof.

\section{RESULTS}

In this paper we have considered square of path $P_{n}^{2}$ graph and proved that it is super harmonic mean labelling graph and have identified a generalization method for M-joins of square of path $P_{n}^{2}$ graph

\section{CONCLUDING REMARKS}

We are investigating on the other types of similar graphs which can be also labelled so as to prove that they are super harmonic mean labelling graph

\section{REFERENCES}

[1] Gallian. J.A, A Dynamic Survey of Graph Labeling, Twentieth edition, 2017

[2] Somasundaram.S and Ponraj.R. Mean labelling of graphs National Academy of Science Letters, Vol.26: .210-21, 2003

[3] Sandhya S.S and Somasundaram. S Harmonic Mean Labelling for Some Special Graphs, International Journal of Mathematical Research, 5(1): 55-61, 2013
[4] Sandhya S.S, Somasundaram. S, Ponraj.R Harmonic Mean Labelling of some cycle related graphs, Int. Journal of Math. Analysis, vol.6 no.40,1997-2005, 2012

[5] Sandhya S S , Somasundaram. S, Ponraj.R Super Harmonic Mean labelling graphs, Shodhganga, Chapter.6

[6] Gross and .Yellen.J, Handbook of graph theory, CRC, Press: 2004 